\title{
Pricing Model for Cloud Computing Services for Research Applications
}

\author{
Inara Opmane, Rihards Balodis \\ Institute of Mathematics and Computer Science, University of Latvia (IMCS UL) \\ Latvia
}

\begin{abstract}
Institute of Mathematics and Computer Science, University of Latvia continues its enduring development of research e-infrastructure. Currently IMCS UL maintains Scientific Cloud computing facility, provides collocation, hosting and virtualization services. As well it operates as a node for online correlation data streaming services from Irbene radio telescope in real time, HPC resources' disposal for computing tasks, usage of big data extracted from data storage for modeling and also for graphic data processing.
\end{abstract}

In this article authors represent pricing policy realized in IMCS UL for cloud computing services. We define the groups of users and prices for services for each user group. Users are split in groups as follows: business companies (defined as Service Price List), research institutions (defined as Service Fee List) and research project partners (defined as Service Coast List). In price list fixed price level can be evaluated with simple cloud computing pricing Model.

Keywords-Cloud Computing Facility, Computing Pricing Policy, Pricing Model, Scientific Cloud fees charging Model

\section{Introduction}

Different layers of research e-infrastructure are available for research today: Cloud Computing Services, GÉANT network, GRID technologies and scientific field-specific einfrastructures - ESFRI (the European Strategy Forum on Research Infrastructures). Institute of Mathematics and Computer Science, University of Latvia (IMCS UL) continues its enduring development of research e-infrastructure, participates in EU international projects such as GÉANT, GN2, GN3, GN3+, GN4, BalticGRID, BG II and EGIInSPIRE, has involved in CLARIN and ELIXIR ESFRI activities. Currently IMCS UL maintains Scientific Cloud unified computing facility, provides collocation, hosting and virtualization services. As well it operates as a node for online correlation data streaming service from Irbene radio telescope in real time, HPC resources' disposal for computing tasks, usage of big data extracted from data storage for modeling and also for graphic data processing.

Computing Facilities at IMCS UL are built as cloud computing system (Open Stack + custom innovations, 2 level hypervisors: VMs and containers) enable us to provide such Scientific Cloud services and Big data services:

- IaaS - Linux or Windows virtual machines - choice of resource and access configurations
- $\quad$ PaaS - SQL, HTTP, Hadoop

- $\quad$ Storage and File services - FTP/FTPS and online NFS services, ownCloud

- $\mathrm{MaaS}$

- High Throughput Computing (HTC)

- GPU/SMP computing

- HDFS distributed file system

- Map Reduce distributed computing service

- Hive data warehouse and HiveQL query engine

- Oozie job scheduling service.

Scientific cloud Facility at IMCS UL technical specification is shown on Table I and development is descript in [1-3].

Use of IMCS UL Scientific Cloud Facility for CPU, RAM, HDD in Years 2008-2016 is shown in Fig.1-3.

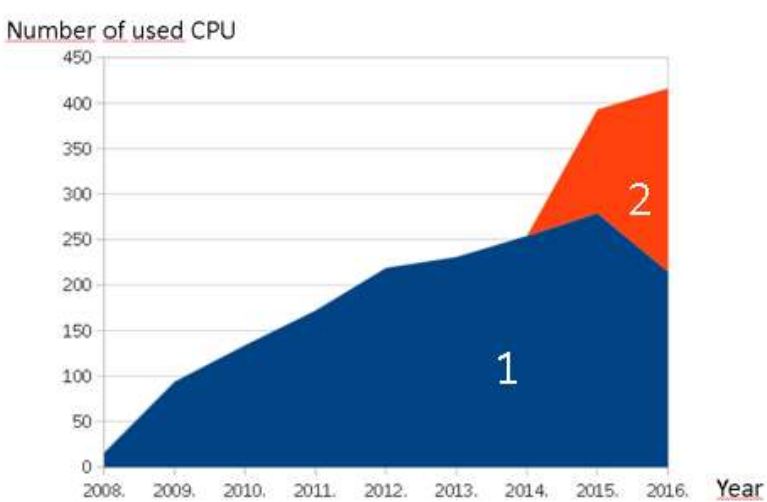

Figure 1. Usage of CPU in 2008-2016. Number 1(Blue)- Scientific Cloud Facility, installed in 2008, Number 2 (Red)- Scientific Cloud Facility, installed in 2015 .

Fig.4 demonstrate Cloud Computing cost accounting model borrowed from [4]. We simplify this model and develop our pricing policy on IaaS with use by time main accounting components: storage, CPU (Core), RAM, software and common facility area networking infrastructure (Rack cost, Area Switching cost, etc.) as Cloud Fixed Cost. Each service price (SaaS, PaaS) is calculated from those basic components (UNITS) prices. 
Proc. of the Fifth Intl. Conf. Advances in Social Science, Economics and Management Study - SEM 2017

Copyright (C) Institute of Research Engineers and Doctors, USA .All rights reserved.

ISBN: 978-1-63248-133-7 doi: 10.15224/ 978-1-63248-133-7-50

TABLE I. $\quad$ SCIENTIFIC CLOUD FACILITY AT IMCS UL

\begin{tabular}{|c|c|}
\hline $\begin{array}{l}\text { Scientific } \\
\text { Cloud } 2008\end{array}$ & $\begin{array}{c}\text { Scientific Cloud } 2015 \\
\text { Much more powerful computing }\end{array}$ \\
\hline $\begin{array}{l}\text { SAN network } \\
\text { Redun-dant } \\
\text { FC paths, } \\
6 \text { controllers, } \\
624 \text { SATA+ } \\
\text { 16FC discs } \\
468 \mathrm{~TB} \text { storage } \\
\text { (IBM DS } \\
4700) \\
384 \mathrm{~GB} \text { RAM } \\
\left(8^{*} 48\right) \\
64 \mathrm{Xeon} \text { cores } \\
(8 \times I B M \\
\text { x3650, Intel } \\
\text { E5430) }\end{array}$ & 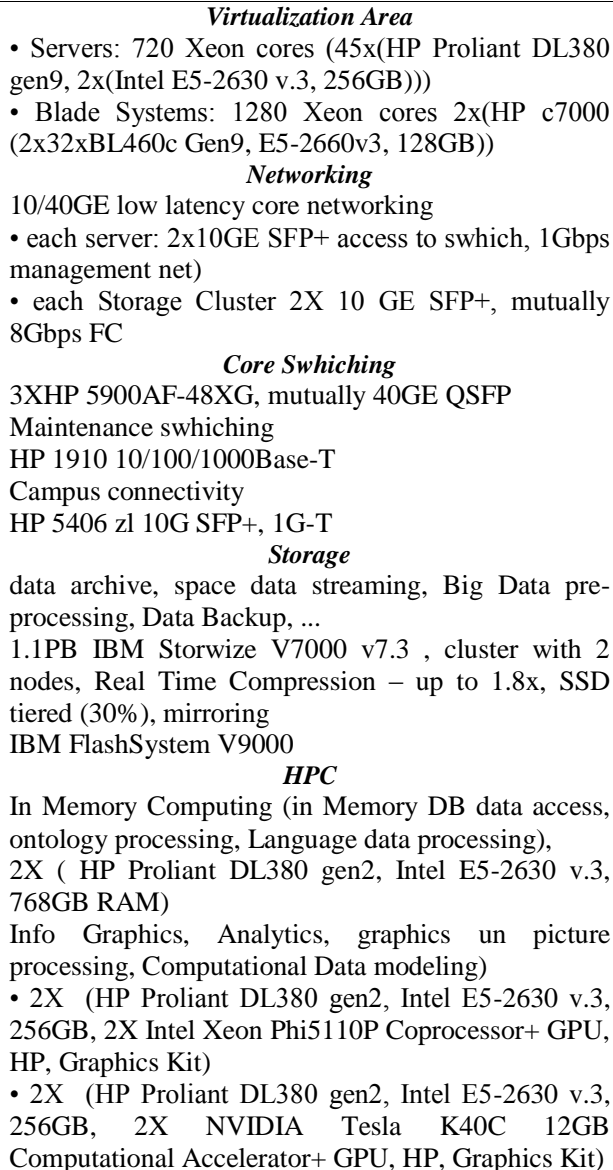 \\
\hline
\end{tabular}

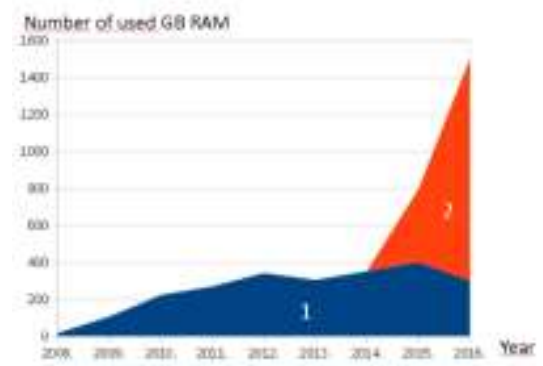

Figure 2. . . Usage of RAM in 2008-2016.(1 -Blue)- Scientific Cloud Facility, installed in 2008, (2 - Red)- Scientific Cloud Facility, installed in 2015.

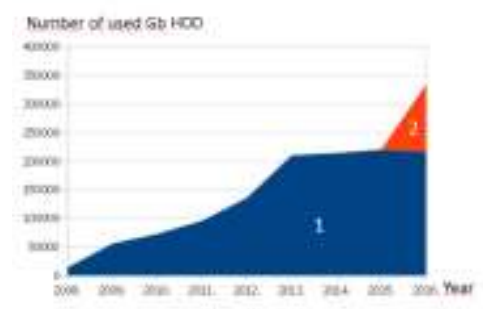

Figure 3. Usage of HDD in 2008-2016. Number (1-Blue)- Scientific Cloud Facility, installed in 2008, (2- Red)- Scientific Cloud Facility, installed in 2015.

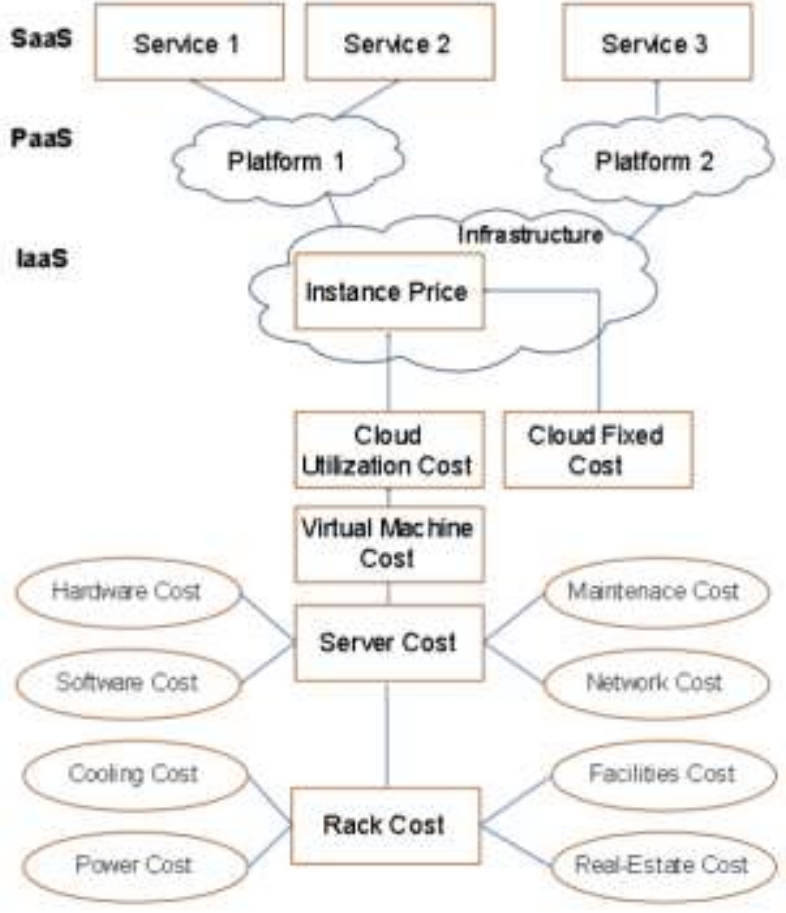

Figure 4. Cloud computing cost accounting model, [4], page 81

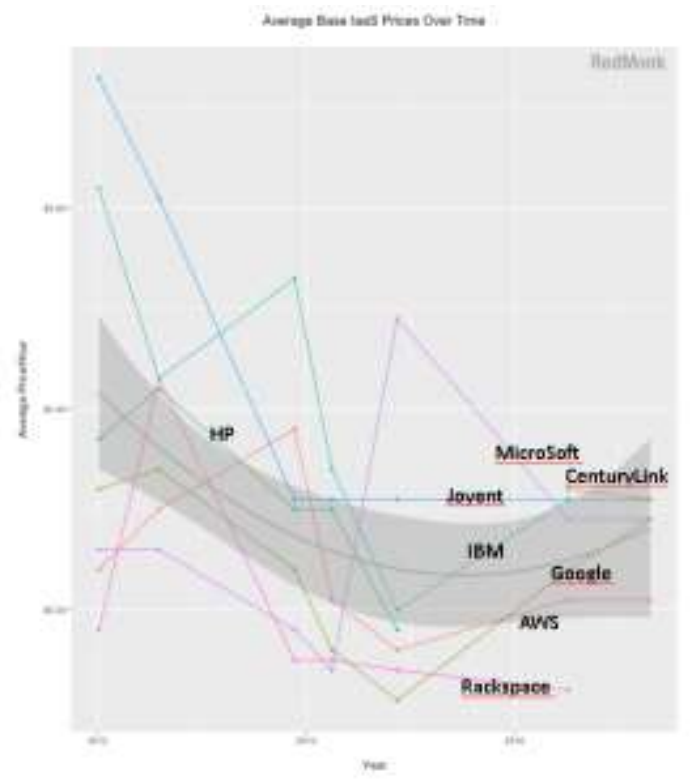

Figure 5. History of Average Base IaaS Prices over Time by RedMonk.

\section{Cloud Computing Pricing Policy}

Cloud Computing usage is different, extensive, spread: we know global Clouds, national Clouds, local Clouds, private Clouds, public Clouds, hybrid Clouds, company Clouds and third-party Clouds. 
Following up Rachel Stephens opinion, from RedMonkthe developer-focused industry analyst company [5] is complicate to compare Cloud Computing Services prices because number of services is great, content of services differs, SLA (Service Level Agreement) is individual for every provider, we don't have standardization for price calculations and real agreement prices often differs from public defined list prices. In figure 5 (copied from RedMonk) see History of price changes over time. Prices are very scattered both in different institutions and in time also.

For Cloud Computing pricing policy several models are developed:

- Consumption-based pricing- you pay for the amount of resources you actually use such as disk space, CPU time and network traffic.

- Subscription-based pricing- you pay for service usage for fixed period of time.

- Advertising-based pricing- user gets a no charge or heavily-discounted service and the provider receives most or all of their revenue from advertisers.

- Market-based pricing- analytical prices derived from existing prices on market for similar services and provider business needs.

Users of our Scientific Cloud are business companies, public research institutes and partners in common research projects with IMCS UL. Our price for service is based on analytic decisions and comparable with global and national market prices, our possibilities and needs. Price for every users group can be calculated from market price according principles demonstrated in Fig.6.

Calculation and formulas are developed analytically and comparative to different centres described in literature. Comments about our solutions:

- Academic Fees und Commercial Price- justification of price difference determines that companies calculate profit $\sim 25 \%$, but IMCS UL is nonprofit organization. According to regulations requirements we must restrict limit of services for commercial users and those prices can not be less then market prices.

- Dynamic Pay-for-Resources and Subscription-we take in account $25 \%$ over workload of resources and cheaper for us is management.

- For project partners (groups E and F)- excluded CapEx (Capital Expenditure) of equipment, software and infrastructure. Cost in Group $\mathrm{E}$ includes equipment renovation and upgrade funding percentage and maintenance expenses, but group F includes only maintenance expenses. All other financing positions must be included in project preparation stage.

IMCS UL Scientific Cloud pricelist shown in TABLE 2.

For every service requested by users price could be calculated from basic pricelist - we may consider service as complex of UNITS - equipment elements, software and infrastructure.

If we compare our prices with analytical data from RedMonk (see Fig.7) there is no significant difference.

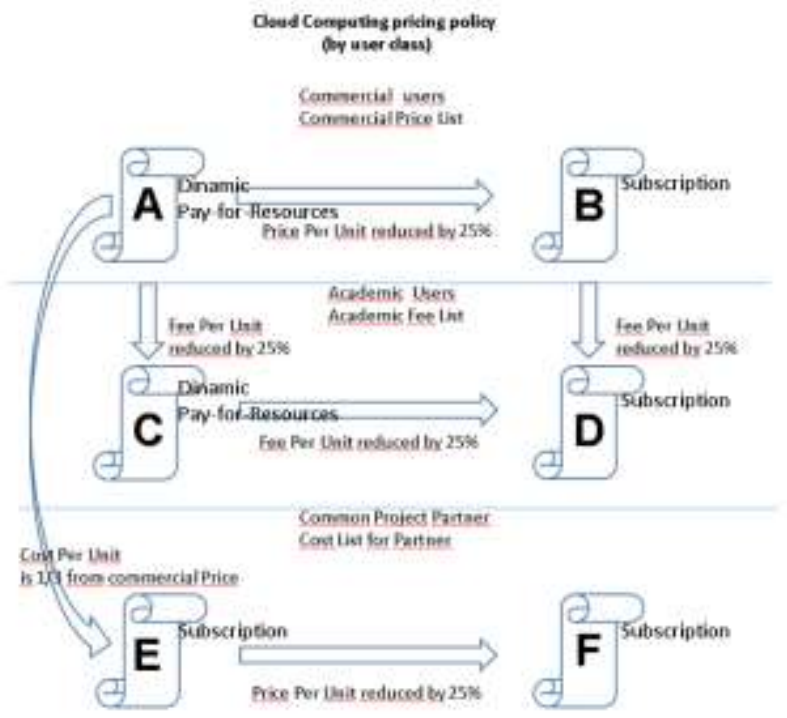

Figure 6. Cloud Computing pricing policy by user group

\section{Simple Model for Setting Price for Service and Revenue Forecasting}

Simple model for modeling incomes, depending of equipment workload, predicted volume of services and their prices are developed. We have assembled Scientific Cloud from base equipment UNITS used e-procurement public procurement methodology [3,5] and therefore obtain price (CapEX- Capital Expenditure) of each equipment UNIT. Therefor we can evaluate benefit of services also.

In model we used such data:

- Cloud Computing Facility Equipment Array, one element for every UNIT (see TABLE III):

(BOXi (numberi, CapExi)), $\mathrm{i}=1,2, \ldots \mathrm{n}$,

where $\left(\mathrm{k}_{\mathrm{i}}, \quad\left(\mathrm{CapEx}_{\mathrm{i}}\right)\right)$ is for one equipment UNIT or software component on witch appropriate Cloud Computing services fulfilled, numberi - maximum number of one UNIT type in Scientific Cloud.

- Cloud Computing Facility Area infrastructure Equipment Array (AREABOXi (CapEx)), i=1,2,...,k,

Where:

AREABOXi is one selected instructure; total CapExi included in this infrastructure. 
Proc. of the Fifth Intl. Conf. Advances in Social Science, Economics and Management Study - SEM 2017

Copyright (C) Institute of Research Engineers and Doctors, USA .All rights reserved.

ISBN: 978-1-63248-133-7 doi: 10.15224/ 978-1-63248-133-7-50

TABLE II. IMCS UL CLOUD COMPUTING PRICELIST

\begin{tabular}{|c|c|c|c|c|c|c|}
\hline \multirow[b]{3}{*}{$\begin{array}{l}\text { Service description } \\
\quad \text { (UNITS) }\end{array}$} & \multicolumn{6}{|c|}{ Price per Month (or reduced to Month), EUR, without VAT } \\
\hline & \multicolumn{2}{|c|}{$\begin{array}{c}\text { Price } \\
\text { Commercial }\end{array}$} & \multicolumn{2}{|c|}{$\begin{array}{c}\text { Fee } \\
\text { Academic }\end{array}$} & \multicolumn{2}{|c|}{$\begin{array}{c}\text { Cost in } \\
\text { common } \\
\text { project }\end{array}$} \\
\hline & $\begin{array}{c}A \\
\text { In Column } \\
\text { indicated } \\
\text { Value is Per } \\
\text { Month* “ } \\
\end{array}$ & $\begin{array}{c}\text { B } \\
\text { Sub } \\
\text { Scription }\end{array}$ & $\begin{array}{c}C \\
\text { In Column } \\
\text { indicated } \\
\text { Value is Per } \\
\text { Month* } \\
\end{array}$ & $\begin{array}{c}\text { D } \\
\text { Sub } \\
\text { Scription }\end{array}$ & $\begin{array}{c}E \\
\text { Non Academic }\end{array}$ & $\begin{array}{c}F \\
\text { Academic }\end{array}$ \\
\hline \multicolumn{7}{|c|}{$C P U$} \\
\hline Core (Intel E5 2630v.3) & 17,80 & 13,00 & 13,00 & 10,00 & 5,93 & 4,45 \\
\hline \multicolumn{7}{|c|}{$R A M, 1 G B$} \\
\hline DDR4, up to $768 \mathrm{~GB}$ & 7,11 & 5,33 & 5,33 & 4,00 & 2,37 & 1,78 \\
\hline \multicolumn{7}{|c|}{ Server HDD, $1 \mathrm{~GB}$} \\
\hline SAS HDD $10 \mathrm{k}$ rpm, up to $300 \mathrm{~GB}$ & 0,82 & 0,62 & 0,62 & 0,46 & 0,27 & 0,20 \\
\hline \multicolumn{7}{|c|}{ Accelerator (without server cost) } \\
\hline $\begin{array}{lcccc}\text { NVIDIA } & \text { Tesla } & \text { K40C } & \text { 12GB } & \text { Computational } \\
\text { Accelerator+GPU, HP, Graphics Kit } & \end{array}$ & 256,00 & 192,00 & 192,00 & 144,00 & 85,33 & 64,00 \\
\hline Intel Xeon Phi5110P Coprocessor+GPU, HP, Graphics Kit & 128,00 & 96,00 & 96,00 & 72,00 & 42,67 & 32,00 \\
\hline \multicolumn{7}{|c|}{ Storage, $1 \mathrm{~GB}$} \\
\hline $\begin{array}{l}\text { IBM Storwize V7000v7.3, cluster with } 2 \text { nodes. Real Time } \\
\text { Compression, SSD tiered }(30 \%) \text { and data access } \\
\text { optimization }\end{array}$ & 0,39 & 0,29 & 0,29 & 0,22 & 0,13 & 0,10 \\
\hline $\begin{array}{l}\text { IBM Storwize V7000v7.3,..+ mirroring }+ \text { data Access } \\
\text { optimization with IBM FlashSystem V90000 }\end{array}$ & 0,44 & 0,33 & 0,33 & 0,25 & 0,25 & 0,11 \\
\hline Usage of IBM FlashSystem V9000 (without Storwize) & 0,90 & 0,68 & 0,68 & 0,51 & 0,30 & 0,22 \\
\hline $\begin{array}{ll}\text { Data streaming in Storwize with } & \text { FlashSystem } \\
\text { V9000 } & \end{array}$ & 0,26 & 0,20 & 0,20 & 0,15 & 0,09 & 0,06 \\
\hline Passive data stored in Storwize & 0,13 & 0,10 & 0,10 & 0,075 & 0,04 & 0,03 \\
\hline Data stored in BackUp & 0,23 & 0,17 & 0,17 & 0,13 & 0,08 & 0,06 \\
\hline SAN- Networking infrastructure & 16.00 & 12.00 & 12.00 & 9.00 & 5.30 & 4.00 \\
\hline
\end{tabular}

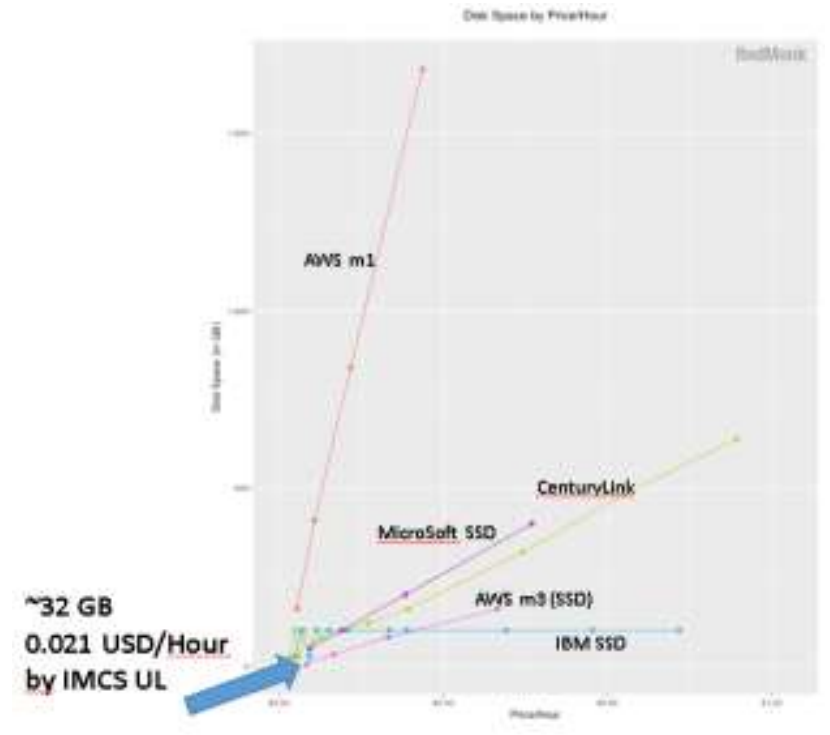

Figure 7. IMCS UL Storage price comparative with redMonk analysis.

For example infrastructure is computing area networking solution: switches, interfaces e.tc.

- Cloud Computing Facility inclusion List
List of subordinate equipment UNITS and infrastructure necessary for operation, for example, infrstructure for accelerator implementation: virtual server, core, RAM, HDD, AREABOXi etc.

- Cloud Computing Facility Services List (see exampleTABLE II):

(SERVICEi (costi)) $\mathrm{i}=1,2, \ldots ., \mathrm{m}$

- Services and Equipment UNIT relevance vector (see TABLE IV),

For example, virtual server contains CORE(number), RAM(number), HDD (number), Storwize storage (number) e.t.c.

- Forecast of Cloud Computing Facility workload vector by services

10 clients $<=($ SERVICEi $)<=20$ clients, $\mathrm{i}=1,2, \ldots \mathrm{h}$

- Forecast of equipment and infrastructure workload vector

$\mathrm{A} \%<=(\mathrm{BOXi})<=\mathrm{B} \%$

For example, use of CORE 30\%-50\%, average in month.

With those data we can:

- calculate price of services; 
TABLE III. EQUIPMENT ARRAY+ NETWORKING INFRASTRUCTURE+ UNIT INCLUSION LIST

\begin{tabular}{|c|c|c|c|}
\hline Equipment unit & $\begin{array}{c}\text { CapEx for } \\
\text { Unit,EUR } \\
\text { without VAT }\end{array}$ & $\begin{array}{c}\text { UNIT inclusion } \\
\text { list }\end{array}$ & $\begin{array}{c}\text { Max } \\
\text { number } \\
\text { in } \\
\text { Scienti- } \\
\text { fic }\end{array}$ \\
\hline $\begin{array}{l}\text { Core (Intel E5 } \\
2630 \mathrm{v} .3)\end{array}$ & 92000.00 & - & 1840 \\
\hline Server & 224498.25 & $\begin{array}{l}\text { CORE(816), } \\
\text { RAM(51*250), } \\
\text { HDD951*300) }\end{array}$ & 51 \\
\hline Server2 & 419748.00 & $\begin{array}{l}\text { CORE }(1280), \\
\operatorname{RAM}(64 * 250), \\
\operatorname{HDD}(64 * 300)\end{array}$ & 64 \\
\hline RAM,DDR4, GB & 22026.48 & Server & 1536GB \\
\hline $\begin{array}{l}\text { SAS HDD } 10 k \\
\text { rpm, GB }\end{array}$ & 30161.00 & - & $34500 \mathrm{~GB}$ \\
\hline $\begin{array}{lr}\text { NVIDIA } & \text { Tesla } \\
\text { K40C } \quad 12 G B \\
\text { Computational } \\
\text { Accelerator+GPU }\end{array}$ & 18185.36 & - & 4 \\
\hline $\begin{array}{l}\text { Intel Xeon } \\
\text { Phi5110P } \\
\text { Coprocessor+GPU }\end{array}$ & 10602.80 & - & 4 \\
\hline $\begin{array}{l}\text { IBM Storwize } \\
\text { V7000v7.3, } 1 \mathrm{~GB} \\
\text { (with } \\
\text { Compression, SSD } \\
\text { tiered) }\end{array}$ & 589392.00 & $\begin{array}{l}\text { Infrastructure: } \\
\text { SAN }\end{array}$ & $1.1 \mathrm{PTB}$ \\
\hline Storwize+ Mirrorig & 9576.00 & Storwize & 1.1PTB \\
\hline $\begin{array}{l}\text { IBM Storwize } \\
\text { V7000v7.3,+ } \\
\text { mirroring + data } \\
\text { Access } \\
\text { optimization with } \\
\text { IBM FlashSystem } \\
\text { V90000 }\end{array}$ & 842887.00 & $\begin{array}{l}\text { Infrastructure: } \\
\text { SAN, } \\
\text { Managament }\end{array}$ & $1.1 \mathrm{PTB}$ \\
\hline $\begin{array}{l}\text { Usage of IBM } \\
\text { FlashSystem } \\
\text { V9000 (without } \\
\text { Storwize) }\end{array}$ & 243919.00 & $\begin{array}{l}\text { Infrastructure: } \\
\text { SAN, } \\
\text { Managament }\end{array}$ & $32 \mathrm{~TB}$ \\
\hline $\begin{array}{l}\text { SAN- Networking } \\
\text { infrastructure }\end{array}$ & 118688.80 & - & 1 \\
\hline
\end{tabular}

TABLE IV. Services Cost CALCUlation EXAMPLE OF SERVICES

\begin{tabular}{|l|l|}
\hline $\begin{array}{c}\text { Service } \\
\text { (UNIT relevance list) }\end{array}$ & \multicolumn{1}{c|}{$\begin{array}{c}\text { Cost calculation (see price in } \\
\text { TABLE II column F also). }\end{array}$} \\
\hline Virtual server- (CORE $=38$, & $4.45 €^{*} 38+1.78 €^{*} 900+64.00 €^{*} 2+$ \\
RAM=900GB,GPU- & $0.20 €^{*} 100+0.10 € * 12000+4.00$ \\
TESLA $=2, \mathrm{HDD}=100 \mathrm{~GB}$, & \\
STORWIZE $=12000 \mathrm{~GB}, \mathrm{SAN})$ & \\
\hline Virtual server2- $(\mathrm{CORE}=12$, & $4.45 €^{*} 12+1.78 €^{*} 80+0.20 €^{*} 150$ \\
RAM=80GB,HDD=150GB, & $+0.10 €^{*} 80000+4.00$ \\
STORWIZE $=80000 \mathrm{~GB}, \mathrm{SAN})$ & \\
\hline
\end{tabular}

-minimum and maximum of incomes based on forecast of usage (services, equipment);

- benefit of equipment;

-if we know total needed income for maintenance, in vice versa calculation direction, we can evaluate approximate price for services group or service.

\section{CONCLUSIONS}

Wide range of Cloud computing services are provided in global market and costs for services are very different. Author's idea was for cloud computing services define simple elements (UNITS) and determine cost for those UNITS. Then cost for service we can calculate from relevant collection of UNITS.

There are two kind of payments for services - pay per-use and subscription. Costs for cloud computing services are defined for three types of users - commercial companies, research institutions that include universities also and IMCS UL project partners. Invoice is settled according to chosen kind of service and user group.

\section{References}

[1] Rihards Balodis, Inara Opmane, Leo Truksans. Unified computing facility design based on open source software. p.337- 342in 2012 International Conference on Systems and Informatics (ICSAI 2012) 19.20. May 2012 Yantai University

IEEE Catalog Number: CFP1273R-CDR ISBN: 978-1-4673-0197-8 IEEExplore Digital Library DOI: 10.1109/ICSAI.2012.6223629

[2] Rihards Balodis, Inara Opmane. Research E-Infrastructure Upgrade Project at IMCS UL. 2012 5th Romania Tier 2 Federation Grid, Cloud\& High Performance Computing Science. 25-27 October 2012 ClujNapoca, Romania Proceedings p. 41-44, In CD IEEECatalog Number CFP12327-CDR, ISBN: 978-973-662-711-8

[3] Rihards Balodis, Inara Opmane. Milestones of complex computing facility assembling . Grid, Cloud \& High Performance Computing in Science. RO-LCG 2015,25-30 October 2015, Cluj-Napoca, Romania, IEEE Catalog Number: CFP15ROL-CDR, ISBN 978-606-737-039-3

[4] Artan Mazrekaj, Isak Shabani, Besmir Sejdiu Pricing Schemes in Cloud Computing: An Overview (IJACSA) International Journal of Advanced Computer Science and Applications, Vol. 7, No. 2, 2016 p 80-86

[5] http://redmonk.com/rstephens/2017/05/26/iaas-pricing-patterns-andtrends-2017, IaaS Pricing Patterns and Trends, By Rachel Stephens May 26, 2017

[6] Rihards Balodis, Inara Opmane. Procurement Management Experience of Scientific Cloud Facility Set Up. ACMASS-6194, ACMASS 2015, Annual Conference on Management and Social Sciences. 2.-4. September, 2015. Kuala Lumpur, Malaysia, ISBN 978-986-89298-3-8, www.acmass.org

About Author (s):

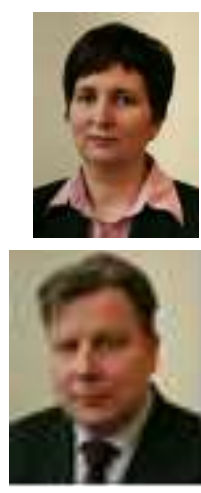

Director of the Institute of Mathematics and Computer Science, University of Latvia (www.lumii.lv). Doctoral Student in Management at the University of Latvia.

R\&D Director, Dr. Computer Science, of the Institute of Mathematics and Computer Science, University of Latvia (www.lumii.lv). 